TEKNIK, 41 (1), 2020, 14-19

\title{
Sealing Performance Layered Metal Gasket Based on the Simulation Method
}

\author{
I Made Gatot Karohika ${ }^{1 *}$, Shigeyuki Haruyama ${ }^{2}$, I Nyoman Gde Antara ${ }^{1}$, I Nyoman Budiarsa ${ }^{1}$, I Made Dwi \\ Budiana Penindra ${ }^{1}$ \\ ${ }^{1}$ Department of Mechanical Engineering, Faculty of Engineering, University of Udayana, \\ Jl. Raya Kampus Unud, Jimbaran, Kec. Kuta Sel., Kabupaten Badung, Bali, Indonesia 80361 \\ ${ }^{2}$ Graduate School of Innovation and Technology Management, Yamaguchi University, \\ 2-16-1 Tokiwadai, Ube, Yamaguchi 755-8611, Japan
}

\begin{abstract}
Studies for corrugated metal gaskets are still ongoing to improve its performance. This is considered to be a single gasket with SUS304 material when contact with flanges that have greater surface roughness, reduced contact width and plastic deformed contact surfaces are incomplete and cannot fill the surface roughness of flanged flanges. The use of softer material than the base material as a surface covering material is used to improve the performance of the gasket. In this study, therefore the effect of modulus of elasticity ratio and thickness ratio on contact width and contact stress, 25A three-layer metal gasket was investigated using Finite Element Analysis. The results showed that the material with tangent modulus, Ehal = Eal $/ 150$ had the highest slope for contact width. While the contact width of the plastic mode gasket is higher than the elastic mode gasket.
\end{abstract}

Keywords: contact width, contact stress, layers, gaskets, corrugated, simulation

\section{Introduction}

Gaskets are commonly used in piping systems in many industries because they are effective in preventing leakage are very effective for preventing leakage. There have been several studies on type $25 \mathrm{~A}$ corrugated metal gaskets. Previous research found that the important design parameters for optimizing $25 \mathrm{~A}$ corrugated metal gasket were contact width and contact stress (Saeed et al., 2008). The next research clarifies the relation of leakage evaluation between water pressure and helium leakage rate and the minimum size for contact width founded. In this study, the main parameter to optimize the gasket design used contact width. Increasing the width of the contact will reduce leaks (Choiron et al., 2011). The study continues by involving contact stress conditions (Choiron, Haruyama, \& Kaminishi, 2012). The researchers continue to optimize gaskets based on contact width taking into account the influence of the forming process. The study found that the 400-MPa gasket design was better than the 0-MPa mode gasket based on the Helium leak test (Nurhadiyanto $d k k, 2012$ ). The next study takes into

\footnotetext{
${ }^{*}$ Corresponding author

E-mail: gatot.karohika@unud.ac.id
}

account the effect of flange surface roughness and finds that the finer surface roughness of flanges will have a better sealing performance (Haruyama et al., 2013).

Previous research mention above was using a single material SUS304 as the metal gaskets. Because of the surface roughness of the flange, the single material gasket can only form a macro seal, and therefore the ability to seal the gasket will reduce. From previous studies, it is also known for the 0-MPa mode gasket is still leaking when contact with flange has surface roughness 3.5-micrometer (Nurhadiyanto, et al., 2015). The simulation of the three-layer metal gasket studied to know the defect occurred on the forming process (Karohika \& Antara, 2018). The forming process parameter that influences the final product of metal gasket then studied by the finite element method (Karohika \& Antara, 2019a). The researchers continue to study the effect of dies type on gasket products (Karohika, Antara, \& Budiana, 2019) and its performance for different types of flanges (Karohika \& Antara, 2019b). Further development is needed to improve the performance of the gasket by adding a surface layer, but the surface layer should be softer than the base material so that it will cover the surface roughness of the flange when in contact. Based on this, this study investigates three-layer metal gaskets with a softer surface than the base metal; thus, the sealing 


\section{TEKNIK, 41 (1), 2020, 15}

ability increases between the touching surfaces. The three-layer gasket with SUS304 as the base metal and the soft material as the surface layer is chosen so that when in contact with the flange it will form a micro seal to cover the roughness of the flange.

This paper aimed to study the metal gasket performance that influences the different material layers and tangent material layers. The metal gasket performance can be associated with contact width and contact stress. Contact width and contact stress are determined by simulation analysis based on elastic and plastic conditions.

\section{Material and Method}

The type of metal gasket (CMG) used in this study are corrugated. The form of the gasket is produced by the mold press. Three layers of sheet metal are assumed to be fully bound; consequently, interface delamination is beyond the scope of this paper. The dimensions of the gasket are based on previous research with the thickness (T) $1.2 \mathrm{~mm}$ for elastic mode, $1.5 \mathrm{~mm}$ for plastic mode, and length (L) $19.5 \mathrm{~mm}$ (Fig. 1) (Nurhadiyanto et al., 2012). In this study, the thickness of the surface layer (T2) was $0.1 \mathrm{~mm}$. The core material (SUS304) has the characteristic modulus of elasticity (Esus304) is $210 \mathrm{GPa}$, the nominal stress ( $\sigma y s u s 304$ ) is $398.83 \mathrm{MPa}$, and the tangent modulus $\left(\mathrm{E}_{\mathrm{T}}\right)$ is 1900.53 $\mathrm{MPa}$.

The layer material uses 3 types of materials that softer than the core material. The modulus elasticity of material 1 (Mat1) has (E1) 0.35 x Esus304, material 2 (Mat2) has (E2) 0.65 x Esus304, Material 3 (Mat3) has (E3) is $0.9 \times$ Esus304. The nominal stress of material 1 $(\sigma 1)$ is $0.2 \times$ osus 304 , the nominal stress of material 2 $(\sigma 2)$ is $0.35 \times$ osus 304 , the nominal stress of material 3 $(\sigma 3)$ is $0.5 \mathrm{x}$ osus304. The working hardening coefficient used 3 levels ( $E h=E / 50, E / 100, E / 150)$ for each layer material. Next, the gasket with material layer 1 (mat1), Material 2 (mat2) and Material 3 (mat3) we call mat1 / SUS304 / mat1, mat2 / SUS304 / mat2, and mat3 / SUS304 / mat3.

The behavior of elastoplastic gaskets was analyzed using FEM software, MSC. Marc. Fig.2 shows the simulation modeling. In this modeling using axissymmetric analysis, isoperimetric quad type 10 solid elements, deformable-body for the gasket. In this study, the gasket model was divided into two simulation stages using forming and tightening simulations. First, using the assumption of two dimensions, the axis-symmetric model is adopted to simulate the formation process in the axial direction between the upper and lower dies. Second, the press mold is then compressed in the axial direction between the upper and lower flanges to form the shape of the gasket produced. Then, the tightening simulation process to get the relationship between axial force, average contact stress, and contact width curve. The rigid bodies assumed for the flanges and die. Furthermore, the evaluation of contact stress and contact width is carried out on the convex gasket parts, which are effective for reducing leakage.

In this study, the material was assumed to follow the bilinear strain hardening isotropic model. Initially, elastic material behavior is characterized by Modulus Young (E) starting at uniaxial stress $\sigma y$. After that, the material response is elastic-plastic with the local tangent to the curve which continuously varies and is referred to as modulus tangent elastic-plastic (ET) (Figure 3). During our nonlinear analysis with an iterative procedure, the Newton-Raphson method was used to solve the equilibrium equation consisting of finite strain plasticity with the multiplication decomposition of the deformation gradient.

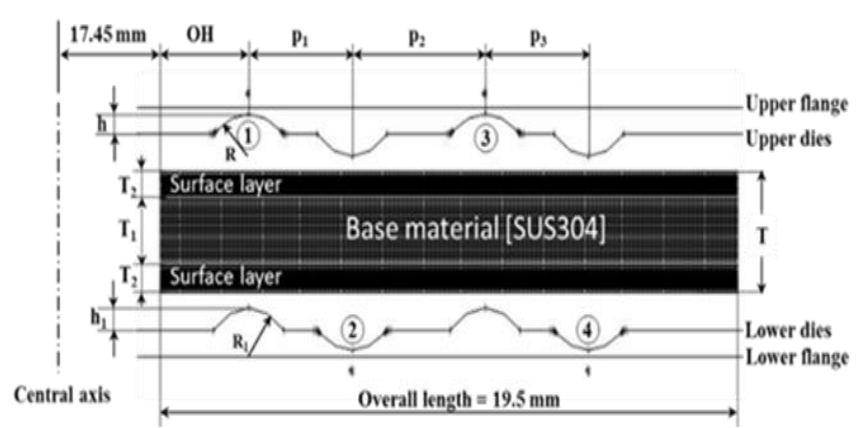

Figure 1. Three-layer metal sheets design.

Table 1. CMG dimension

\begin{tabular}{lcc}
\hline Design Parameter & 0-Mpa & 400-MPa \\
\hline Over Hang $(\mathrm{OH})[\mathrm{mm}]$ & 3 & 3 \\
Pitch 1 (p1) [mm] & 4.5 & 3.5 \\
Pitch 2 (p2) [mm] & 4.5 & 4.5 \\
Pitch 3 (p3) [mm] & 4.5 & 3.5 \\
Lip Height (h)[mm] & 0.35 & 0.3 \\
Lip Height (h1)[mm] & 0.39 & 0.33 \\
Convex Radius (R)[mm] & 3.5 & 2.5 \\
Convex Radius (R1)[mm] & 3.2 & 2.3 \\
Thickness gasket total $(\mathrm{T})[\mathrm{mm}]$ & 1.2 & 1.5 \\
Surface layer thickness $\left(\mathrm{T}_{2}\right)[\mathrm{mm}]$ & 0.1 & 0.1 \\
\hline
\end{tabular}

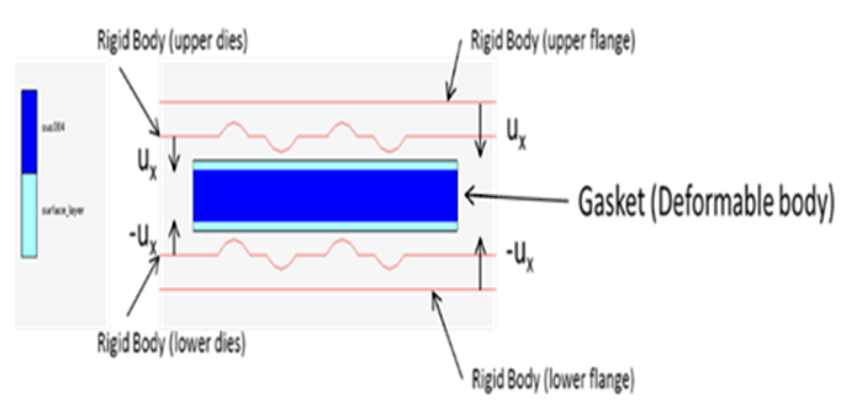

Figure 2. Model simulation of the layered gasket 


\section{TEKNIK, 41 (1), 2020, 16}

From the results of the simulation, based on the contact status, the contact width and contact stress is determined by convert data from MSC. Marc to the Microsoft Excel (Fig.4). If there is contact the values are 1 and 0 for no contacts, respectively. In corrugated metal gasket, the convex portion is effective for preventing leaks taken as part of the evaluation. The contact surface increases because of the increase in tightening force to the gasket.

The gasket design used is based on previous research without considering the contact stress distribution called 0-MPa mode. Gasket design taking into account the plastic contact stress conditions called 400-MPa mode (Nurhadiyanto et.al., 2012).

\section{Results and Discussion}

Based on previous research, peak 2 and peak 3 are higher than peak 1 and peak 4 for contact width and contact stress. Therefore, in this study, the contact surface and contact stress of the three-layer gasket will be represented by each peak 3 and peak 2 .

The simulation results for the Mat1 / SUS304 / Mat1 gasket in 0-MPa mode are shown in figure 5. This number indicates that with increase the tightening force will cause the contact width to increases. The gasket Mat1 / SUS304 / Mat1 with work hardening coefficients, Eh1 = $\mathrm{E} 1 / 150$ and $\mathrm{Eh} 1=\mathrm{E} 1 / 50$ each has the highest and lowest slope of contact width.

The gasket Mat1 / SUS304 / Mat1 has work hardening coefficients Eh1 = E1 / 50 showing the highest average contact stress tendency compared to the others. The performance of the gasket will keep good if the effective normal stress on the gasket must be higher than the internal pressure test. The internal pressure value use in the piping system test is around $10 \mathrm{MPa}$. A tightening force $100 \mathrm{KN}$, the average contact stress is around $350 \mathrm{MPa}$, therefore, it is 35 times greater than internal pressure.

Fig. 6 shows the simulation results for the Mat2 / SUS304 / Mat2 gasket in 0-MPa mode. Contact width is seen to increase with increasing tightening force. The highest and lowest slope contact widths are owned by Mat2 / SUS304 / Mat2 gaskets with work hardening coefficients, $\mathrm{Eh} 2=\mathrm{E} 2 / 150$ and Eh2 $=\mathrm{E} 2 / 50$ respectively.

The highest average contact stress possessed by Gasket Mat2 / SUS304 / Mat2 has the work hardening coefficient Eh1 = E1 / 50. Average contact stress around $410 \mathrm{MPa}$, generated at a tightening force of $100 \mathrm{KN}$ so that the gasket performance will remain good because the contact pressure is 41 times greater than the internal pressure.

Figures 8, 9, and 10. The simulation results for the gasket in 400-MPa mode Mat1 / SUS304 / Mat1 are shown in figure 8 . It indicates the relation between tightening force with contact width and average contact stress. It shows that increasing the tightening force will cause the contact width and average contact stress also increases. The gasket with work hardening coefficients, Eh1 = E1 / 150 and Eh1 =E1 / 50 has the highest and lowest slope of contact width respectively.

The performance for gasket $400-\mathrm{MPa}$ is shown in The gasket has work hardening coefficients Eh1 = E1/50 showing the highest average contact stress tendency compared to the others. The performance of the gasket will keep good because the effective normal stress on the gasket is around $480 \mathrm{MPa}$ at tightening force $80 \mathrm{KN}$, so it is 48 times higher than the internal pressure test.

Figure 9 shows the performance of the Mat2 / SUS304 / Mat2 gasket in 400-MPa mode. The gasket with work hardening coefficients, Eh2 = E2 / 150 has the highest slope of contact width but has the lowest average contact stress, meanwhile, the gasket with work hardening coefficients Eh1 = E1 / 50 showing the highest average contact stress tendency compared to the others. The performance of the gasket seems to keep good because the average contact stress is around $520 \mathrm{MPa}$ (52 times greater than internal pressure) at tightening force $80 \mathrm{KN}$.

The similar trend simulation results are also shown in figure 10. This figure indicates for the Mat3 / SUS304 / Mat3 gasket in 400-MPa mode that if the tightening force increase causes the contact width increase too. The gasket with work hardening coefficients, Eh3 = E3 / 150 has the highest slope of contact width.

The gasket has work hardening coefficients Eh1 = E1 / 50 produces the highest average contact stress tendency compared to the others. Therefore the performance of the gasket will keep good because at tightening force $80 \mathrm{KN}$, the average contact stress is around $600 \mathrm{MPa}$, it is 60 times greater than internal pressure.

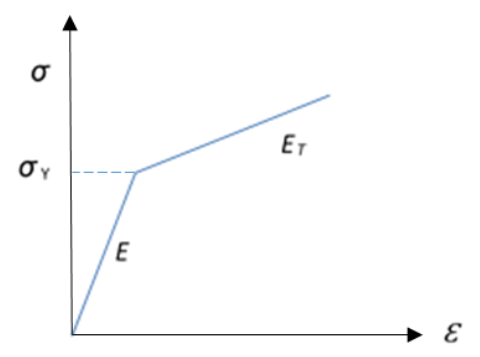

Figure 3. Gasket material model

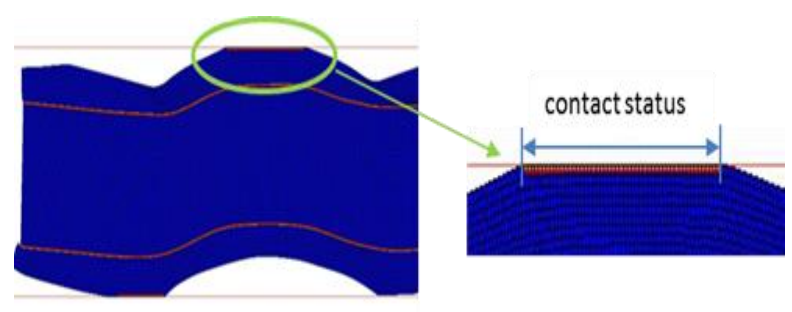

Figure 4. The condition of contact status 


\section{TEKNIK, 41 (1), 2020, 17}

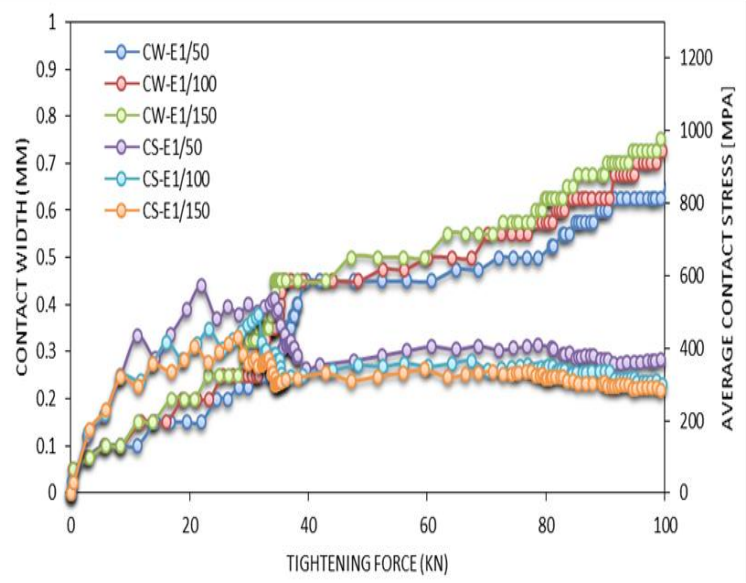

Figure 5. Performance of the gasket 0-MPa mode Mat1 / SUS304 / Mat1.

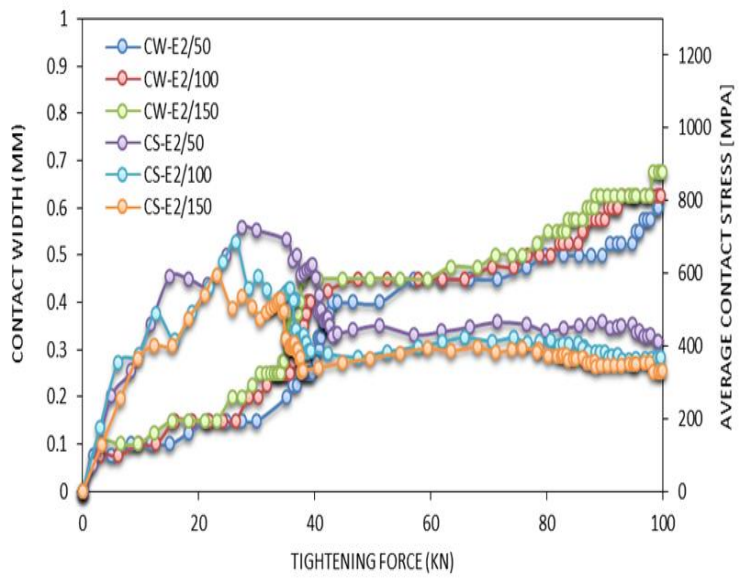

Figure 6. Performance of the gasket 0-MPa mode Mat2 / SUS304 / Mat2.

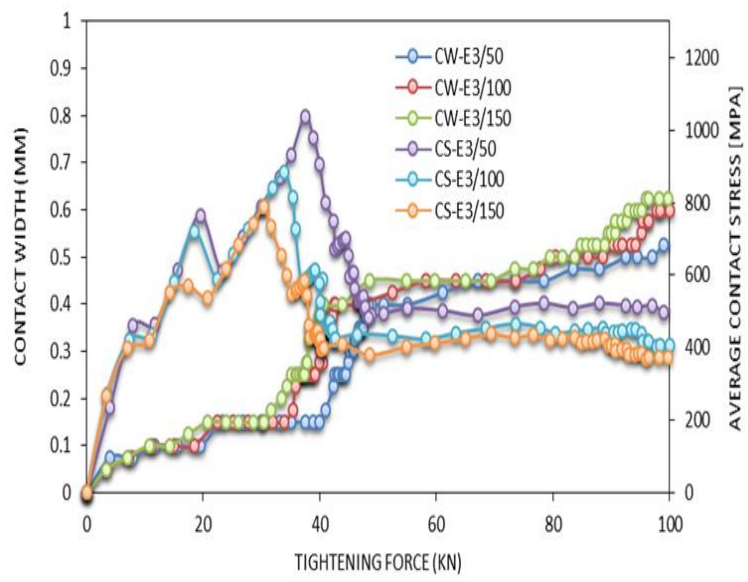

Figure 7. Performance of the gasket 0-MPa mode Mat3 / SUS304 / Mat3

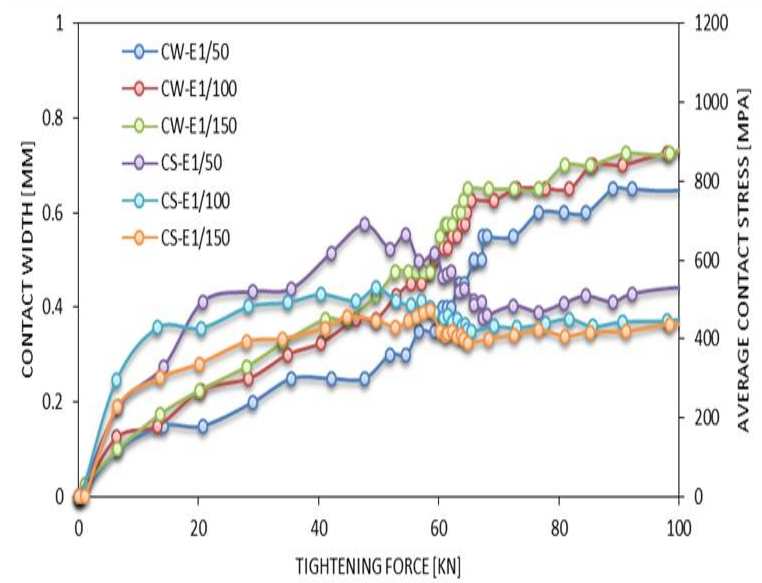

Figure 8. Performance of the gasket 400-MPa mode Mat1 / SUS304 / Mat1

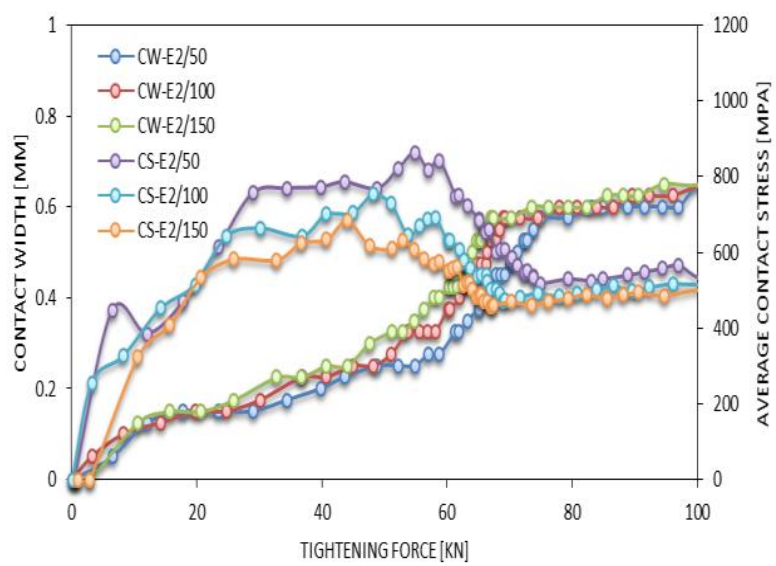

Figure 9. Performance of the 400-MPa mode Mat2 / SUS304 / Mat2

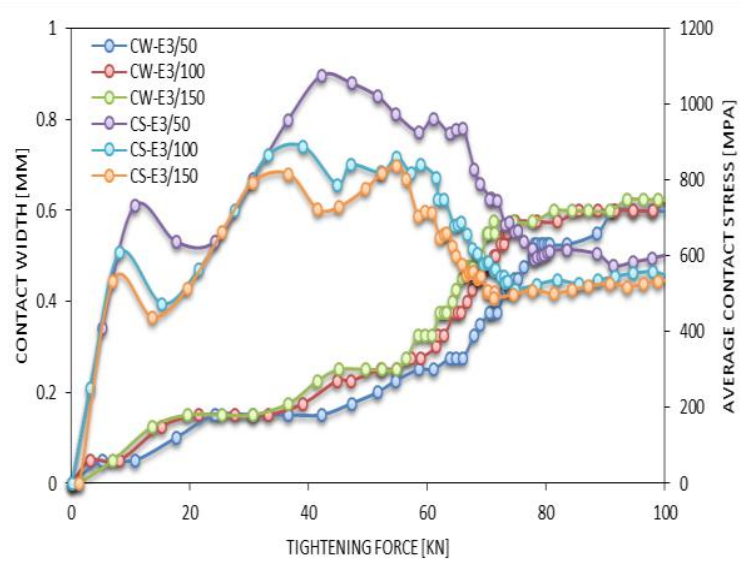

Figure 10. Performance of the gasket 400-MPa mode Mat3 / SUS304 / Mat3 


\section{TEKNIK, 41 (1), 2020, 18}

Based on the simulation results, the average contact stress for the 400-MPa gasket mode is higher than the $0-\mathrm{MPa}$ gasket mode. Gasket with higher average contact stress will produce better tightening to prevent leakage. Higher average contact stress also in correlation with contact width in plastic condition. The gasket has high average contact stress and greater contact width in plastic condition can prevent leakage at low tightening force. Figure 11 and figure 12 show the comparison of the gasket that only used a single material SUS304 with a three-layer. For contact width, three layers of gaskets with mat $1(\mathrm{Eh}=\mathrm{E} 1 / 150) 0.1 \mathrm{~mm}$ layer had a higher slope for both types of gaskets as shown in, because the surface material softer and thinner than the others, therefore when tightened will produce

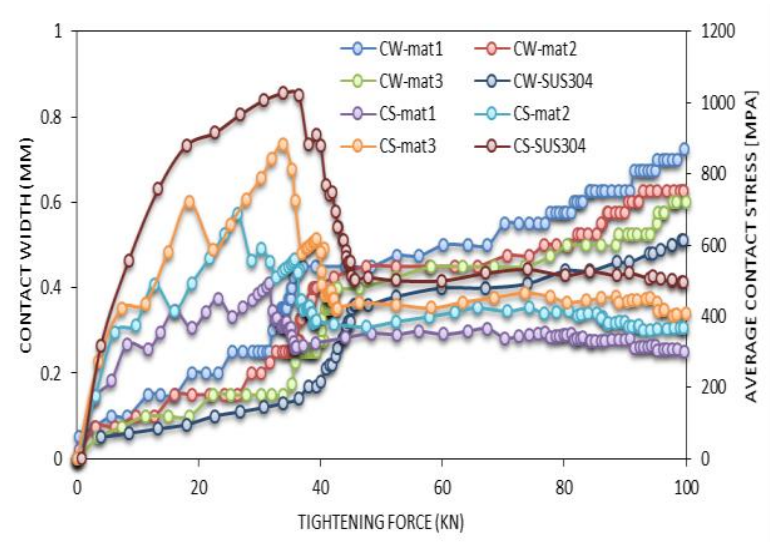

Figure 11. Comparison of performance of type 0-MPa gaskets

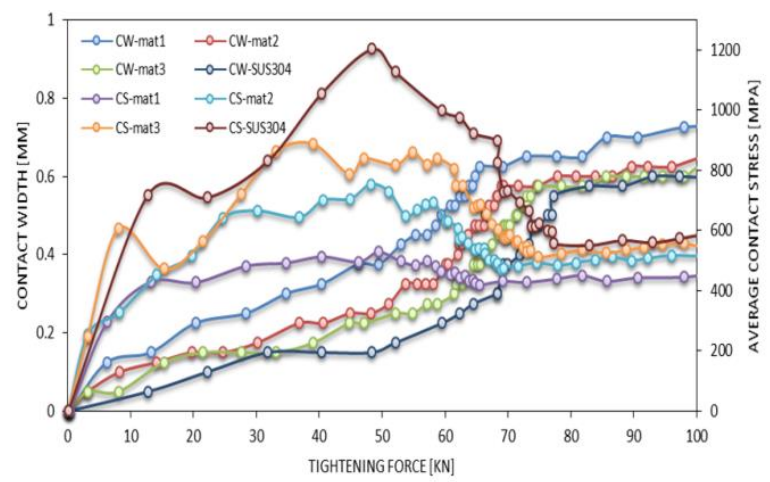

Figure 12. Comparison of performance of type 400MPa gaskets more contact width. Gasket with a higher slope will give better performance at lower tightening force. Figure 13 $\mathrm{a}, \mathrm{b}, \mathrm{c}$ shows the contact width condition for each tightening force, it shows that the three-layer gasket has a greater contact width under conditions of plastic contact stress than the single-layer SUS304. It because the surface material softer than the core material, therefore will more easily deform plastic when contact with the flanges and produce greater contact width under plastic condition than single only SUS304. Gasket with greater contact width under plastic condition will give a good performance. Based on the simulation results it can be stated that three-layer gaskets are better than SUS304 single gaskets but further experiment use water pressure test is needed to validate simulation results.

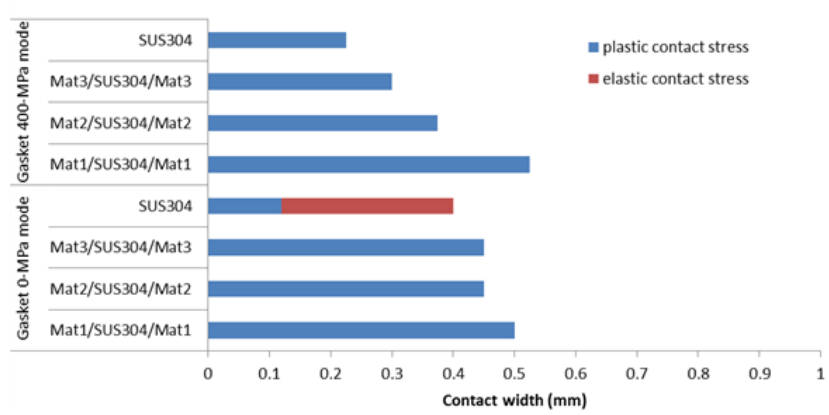

(a) The condition of contact width in a $60 \mathrm{kN}$

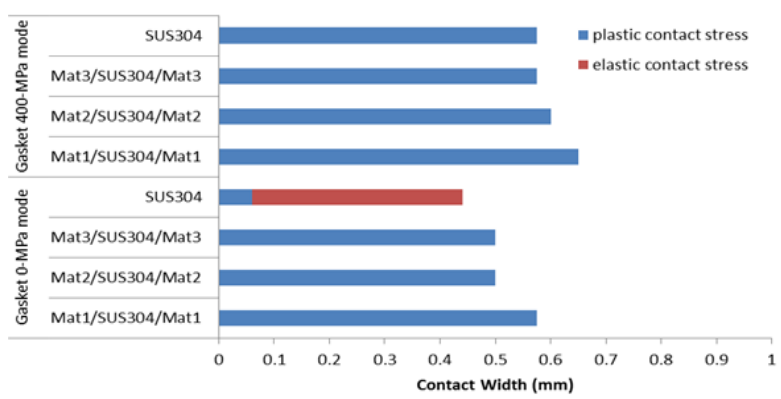

(b) Contact conditions width in $80 \mathrm{kN}$

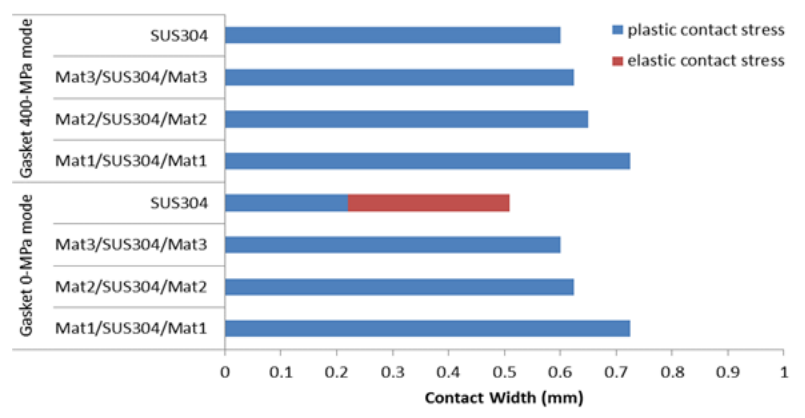

(c) Contact conditions width in a $100 \mathrm{kN}$

Figure 13. Condition of Contact width in each tightening force $(\mathrm{Eh} / \mathrm{E}=1 / 100)$ 


\section{TEKNIK, 41 (1), 2020, 19}

\section{Acknowledgment}

The research is supported through Udayana Invention Research by LPPM Universitas Udayana and Strength of Material laboratory, Yamaguchi University, Japan.

\section{Conclusion}

In this study, from simulation analysis by FEM, we can conclude that for gasket mode the 400-Mpa mode gaskets have higher average contact stress than the 0 -MPa mode gasket. But, the contact width is lower than the $0-\mathrm{MPa}$ mode gasket at $60 \mathrm{kN}$. For axial force $80 \mathrm{kN}$ and $100 \mathrm{kN}$, gasket $400-\mathrm{MPa}$, the mode has a higher contact width and contains contact stress in plastic conditions greater than 0-MPa mode.

For material type, the Mat3 / SUS304 / Mat3 gasket that Eh3 = E3 / 50 shows the highest tendency of the average contact stress compared to the others. The contact width in Mat1 gasket / SUS304 / Mat1 is in contact with flanges with work hardening coefficient, Eh1 = E1 / 150 has the highest slope for both types of gaskets

\section{References}

Choiron, M. A., Haruyama, S., \& Kaminishi, K. (2012). Optimization of new metal gasket design based on contact width involving contact stress consideration. Applied Mechanics and Materials, 110-116(January), 4780-4787.

Choiron, M. A., Kurata, Y., Haruyama, S., \& Kaminishi, K. (2011). Simulation and experimentation on the contact width of new metal gasket for asbestos substitution. International Journal of Aerospace and Mechanical Engineering, 5(4), 283-287.

Haruyama, S., Nurhadiyanto, D., Choiron, M. A., \& Kaminishi, K. (2013). Influence of surface roughness on leakage of new metal gasket. International Journal of Pressure Vessels and Piping, 111, 146-154.
Karohika, I. M.G., \& Antara, I. N. G. (2019a). Gasket Process Parameter in Metal Forming. IOP Conference Series: Earth and Environmental Science. 248(1), 012044.

Karohika, I. M.G., \& Antara, I. N. G. (2019b). The metal gasket sealing performance of bolted flanged with fem analysis. IOP Conference Series: Materials Science and Engineering, 539(1), 012018.

Karohika, I. M.G., Antara, I. N. G., \& Budiana, I. M. D. (2019). Influence of dies type for gasket forming shape. IOP Conference Series: Materials Science and Engineering. 539(1), 012019.

Karohika, I Made Gatot, \& Antara, I. N. G. (2018). Proses Pembentukan Gasket berlapis dengan Metode Elemen Hingga. Jurnal Energi Dan Manufaktur, 11(2), 62-66.

Nurhadiyanto, D., Choiron, M. A., Kaminishi, K., \& Haruyama, S. (2012). Optimization of New 25A-size Metal Gasket Design Based on Contact Width Considering Forming and Contact Stress Effect. International Journal of Mechanical and Mechatronics Engineering, 6(3), 671-675.

Nurhadiyanto, D., Haruyama, S., Kaminishi, K., Gatot Karohika, I. M., \& Mujiyono, D. (2015). Contact Stress and Contact Width Analysis of Corrugated Metal Gasket. Applied Mechanics and Materials, 799-800, 765-769.

Saeed, H. A., Izumi, S., Sakai, S., Haruyama, S., Nagawa, M., \& Noda, H. (2008). Development of New Metallic Gasket and its Optimum Design for Leakage Performance. Journal of Solid Mechanics and Materials Engineering, 2(1), 105-114. 